\title{
Acehnese traditional clothing recognition based on augmented reality using hybrid tracking method
}

\author{
Ahmad Ihsan, Nurul Fadillah, ChichaRizka Gunawan \\ Faculty of Engineering, Samudra University, Indonesia
}

\begin{tabular}{l}
\hline \hline Article Info \\
\hline Article history: \\
Received Feb 13, 2020 \\
Revised Apr 15, 2020 \\
Accepted Apr 29, 2020 \\
\hline
\end{tabular}

\section{Keywords:}

Acehnese traditional clothing Augmented reality Hybrid tracking

\begin{abstract}
Aceh's traditional clothing is cultural heritage in Indonesia. In today's, the problem faced is the lack of media to introduce cultural heritage in Aceh. Therefore was formed a media which could recognition Acehnese traditional clothing using Augmented Reality technology. Augmented Reality technology is used to users can add virtual objects to real environments. In this research, the method used is the Hybrid Tracking method, a Hybrid Tracking method is a combination tracking system of two or more tracking techniques, hybrid tracking is used to get a better tracking system and to get tracking speeds based on better distances. The results showed that the reading of markers by the cameras was greatly influenced by distance, light intensity, marker angle, and size of the device's RAM. The closest distance from the marker to the camera that can display 3D objects is $20 \mathrm{~cm}$ while the farthest distance cannot display 3D objects is $100 \mathrm{~cm}$. And the angle of reading the marker is only around $0^{\circ}$ an angle of $45^{\circ}$. The average distance that can detect markers is $0.5 \mathrm{~m}$, the average time that can be detected is $0.068 \mathrm{sec}$, and the average speed obtained is $7.505 \mathrm{~m} / \mathrm{sec}$.
\end{abstract}

Copyright $@ 2020$ Institute of Advanced Engineering and Science. All rights reserved.

\section{Corresponding Author:}

Ahmad Ihsan,

Faculty of Engineering,

Samudra University, Indonesia.

Email: Ahmadihsan@unsam.ac.id

\section{INTRODUCTION}

Indonesia is a country that has many ethnic groups and is rich in each ethnic culture. The culture that is owned by ethnic Indonesians includes traditional Indonesian clothing. Traditional clothing owned by Indonesia is very much, but the reference information is still lacking. Similarly, the reference was to traditional Acehnese traditional clothing.

Various fields have been applying this sophisticated technology, such as education, tourism, advertising, architecture, and urban scheduling navigation such as indoor building and bus route guidance [1-4]. But in the media of cultural introduction, the use of Augmented Reality technology is still very little. Such conditions led to a lack of knowledge about the many traditional Aceh attire. So that media is needed to be able to introduce traditional clothing attractively and interactively.It is worthwhile to implement $\mathrm{AR}$ in mobile applications since mobile devices are renowned for the high mobility feature and easy to be used by everyone, particularly young people [5].

Augmented Reality known by its English abbreviation AR (augmented reality), is a technology that combines twodimensional and three-dimensional virtual objects into a real three-dimensional environment and projects those virtual objects in real time. Unlike virtual reality that completely supersedes reality, reality is added simply to add or complement reality. Augmented reality (AR) is believed to be the next wave of online learning. New user experiences become possible to afford AR capabilities with the advent of powerful smartphones [6,7]. AR refers to the overlaying of digital content onto the physical objects or locations in the real environment [8]. It is also normally practiced by looking through the camera of devices 
such as a smartphone, tablet, webcam, or a head-mounted display. According to [9] AR can produce an amazing virtual result in which it fits live images or pictures that have been digitized into the user's real surrounding. AR has its resonance with a real environment in which information can be involved and people are able to learn through it. [10]

There are some associated works regarding this topic. Hsu, Chen, and $\mathrm{Wu}$ [11] made use of video as an AR object for teaching the history of computing. They applied thirteen videos of historical figures. Those videos would be appeared on tablet PC screen based on the corresponding figures in the printed textbook captured by the tablet's camera. Eighty-four high school students were involved in the research, divided into two groups. The data results show that students appreciated the method of learning history of computing using AR tools.

Another related topic is research conducted by Azhar, Diah, Ahmad, and Ismail [12]. They created the details of traditional information on history in an interactive way that includes visuals and images to attract people as offered by Augmented Reality (AR).Thus, this research project aims to study the effect of combining AR technology with traditional information to entice people to learn history. The development of the AR application in this project is to enhance the traditional book by providing users with different digital views to view the historical events digitally.

Another related topic is research conducted by Izzaty, Tolle, Dermawi, and Permana [13], the research is conducted to examine which AR objects design which is worthy to be implemented in an augmented book that tells about local Indonesian folktale. In the research, there are three designs of AR objects, and each of them has their specialties. The first design is AR objects that consist of pictures combined with the narrator's voice. The second design is AR objects consist of limited animation and the narrator's voice. And the last design is AR objects consist of short animated video based on the scene in the picture.

The other related work is about interactive learning using AR technology conducted by Ahmad, Munawir, and Fazri [14].In the study, developed augmented reality technology for the introduction of mathematical symbols in the form of symbols of simple mathematical operations that are presented virtually with the aim of helping children of early age in recognizing mathematical symbols and help math lessons more interesting and fun as well provides a variety of learning media to improve the interest of early childhood learning in learning mathematics. And also, the other related work is about interactive learning using AR technology conducted by Reza Andrea, et al [15]. The research contributes in educational technology with an augmented reality media. Textbook is used not only as teaching matters but is also can displaying interactive 3D objects. We implemented marker based tracking method on application and geometry learning for elementary school. It's called "Magic Boosed". Marker based tracking method is very suitable applied in textbook. This marker is suitable applied to the elementary school textbook that is usually printed in black and white [16-18].

In Affan, et al research is to produce Augmented Reality application that could visualize information of Dieng tourism objects, as an interactive, interesting information and tourism promotional media. The user would get information about every tourist attraction in Dieng through the augmented reality application that contains many contents about the sites by scanned Natural Marker that already exist in every Dieng tourist attraction sites with their smartphone [19]. In Rudy Setyadi and Indra Ranggadara is the development of the research carried out an idea to apply the FAST algorithm to augmented reality in its use as a home catalog. The FAST algorithm is implemented in scanning AR markers as detection of home catalog markers to define how well images can be detected and tracked. Different from previous research, researchers will add the home tour feature as an additional multimedia experience that surrounds the house and goes into the house to see in detail and more real. With the application of the augmented reality, the user can more easily get the information about the home in the form of 3D models by aiming the camera to the marker on the catalog [20].

The other related topic is morover to learn the culture such as learning traditional musical instruments [21], learning tample as historical heritage [22], learning the museum objects [23-24], to learn marine mammals [25]. In the research conducted by Adi Putra Andriyani, et al. Besides applying the FAST detection algorithm, the accuracy and processing time of the FAST algorithm in detecting Tajweed have also been investigated using Augmented Reality (AR) technology [26]. Based on studies that have been doing before, the application of Augmented Reality is widely used in the world of education to attract students' interest in learning. But it is still lack in research on the marker tracking speed process. Therefore, it will be building an application that utilizes Augmented Reality technology to recognize Aceh traditional clothing that displays 3D Acehnese traditional clothing objects with better speed. This application uses the hybrid tracking method, which is a method that can perform a marker tracking process faster. It is expected that the application of Augmented Reality based introduction to Aceh traditional clothing using the hybrid tracking method can create a medium the introduction of Acehnese traditional clothing more interactive and interesting. 


\section{RESEARCH METHOD}

The general architecture of the application of Augmented Reality Aceh traditional clothing can be seen in Figure 1.

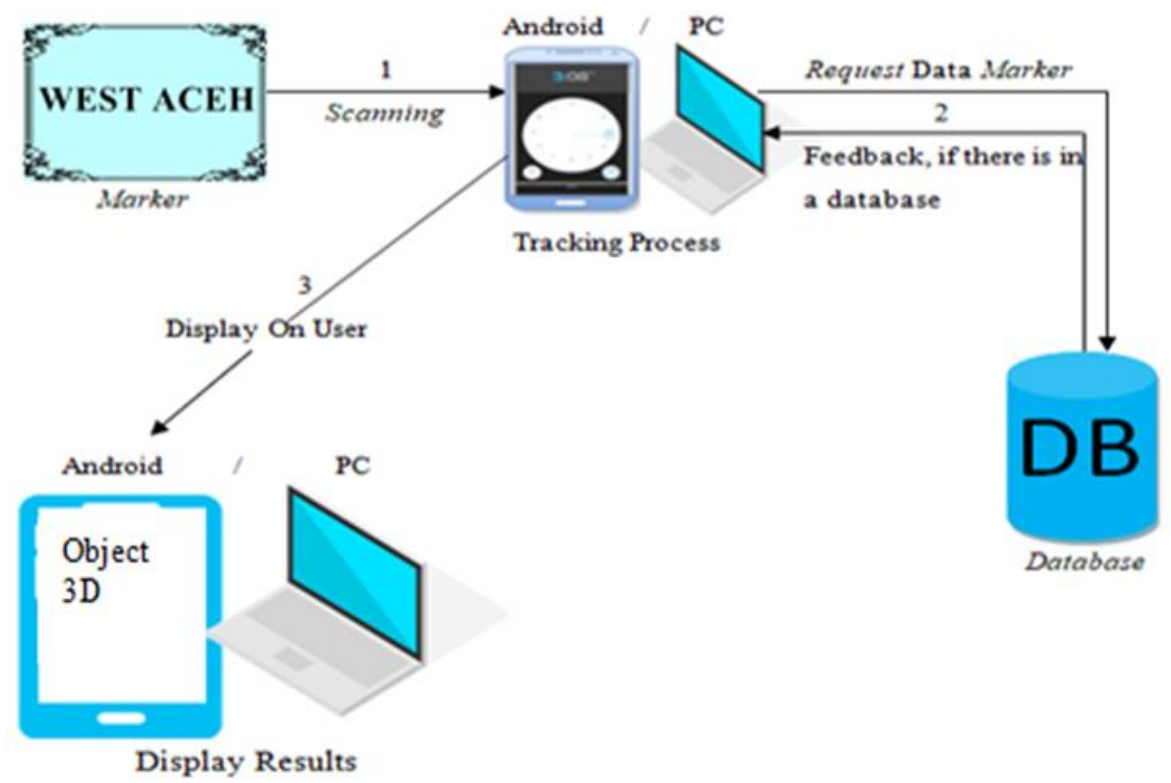

Figure 1. General architecture of augmented reality applications

It can explain that:

a) The process of the user (user) scans the image which is a marker object using an Android smartphone camera or PC webcam, the marker used is in the form of reading the name of the district from the clothes using Times New Roman written on thick paper that does not reflect light.

b) The request process for the marker data and the Vuforia process sends marker feedback that has been input. The process of requesting data stored in the application database, then the database sends the requested data to the application on android smartphones and PC.

c) The Application Process displays data in the form of Acehnese traditional clothing 3D objects on the android smartphone screen and the PC screen.

The Augmented Reality program can be running on Android smartphones and PC. The tracking process has a different time tracking speed which is by the size of the RAM a device, the tracking time of the program will be faster using a device with large RAM size, which is the high RAM the device has, the fast the device performs the tracking process for markers.

\section{RESULTS AND ANALYSIS}

\subsection{Testing writing size on marker}

Testing the size of the writing on the marker is done with the same marker size but the size of the writing on the marker is different. The type of writing used is Times New Roman with sizes 15, 30, 45, 60 , and 75 , can be seen in Table 1 .

It is found that with different writing sizes, 3D objects can appear. But 3D objects that appear different in size because they follow the size of the writing in the marker. The smaller the size of the writing on the marker then the $3 \mathrm{D}$ object that appears is also small.

Table 1. Table of writing size test results on markers

\begin{tabular}{cc}
\hline Writing Size & Description \\
\hline 15 & Detected \\
30 & Detected \\
45 & Detected \\
60 & Detected \\
75 & Detected \\
\hline
\end{tabular}




\subsection{Testing the type of writing on the marker}

Testing the type of writing on the marker is done with the same size of writing, which is 45 but the type of writing in the marker is different. The types of writing used are Times New Roman, Arial, Algerian, Bauhaus 93, and Calibri. Based on Table 2, it can be found that with different types of writing 3D objects cannot appear. 3D objects can only appear if using the Times New Roman type.

Table 2. Table of writing type testing results on markers

\begin{tabular}{cc}
\hline Writing Type & Description \\
\hline Times New Roman & Detected \\
Arial & Not detected \\
Algerian & Not detected \\
Bauhaus 93 & Not detected \\
Calibri & Not detected \\
\hline
\end{tabular}

\subsection{Distance testing}

In the testing distance, the closer the distance between the camera and the marker, the larger the size of the marker detected by the camera so that the marker image can be captured properly. Can be seen in Table 3. Different times are obtained. The farther the marker distance with the camera, the longer the object rendering process will occur. At a distance of $100 \mathrm{~cm}$, the marker is not detected because there is not enough detail to correctly identify the pattern in the marker. The table above has distance values in units of $\mathrm{cm}$ and time in units of milliseconds (ms). The unit of distance $\mathrm{cm}$ is changed to $\mathrm{m}$ and the unit of time $\mathrm{ms}$ is changed to $\mathrm{s}$, then the value of distance and time is obtained as in Table 4.

It is found that the tracking speed results in different marker distances. In this test, a marker distance of the camera was carried out as far as $20 \mathrm{~cm}$ to $100 \mathrm{~cm}$ which obtained results from the scanning time of the marker against distance as shown in Table 4 and clarified in the graph of the tracking speed in Figure 2.

Table 3. Table marker distance test results

\begin{tabular}{ccc}
\hline Distance $(\mathrm{cm})$ & Time $(\mathrm{ms})$ & Description \\
\hline 20 & 00.35 & Detected \\
40 & 00.48 & Detected \\
60 & 00.62 & Detected \\
80 & 01.27 & Detected \\
100 & - & Not Detected \\
\hline
\end{tabular}

Table 4. Table of tracking speed results

\begin{tabular}{cccc}
\hline No. & $\mathrm{s}$ & $\mathrm{T}$ & $\mathrm{V}$ \\
\hline 1. & $0,2 \mathrm{~m}$ & $0,035 \mathrm{~s}$ & $5,71 \mathrm{~m} / \mathrm{s}$ \\
2. & $0,4 \mathrm{~m}$ & $0,048 \mathrm{~s}$ & $8,33 \mathrm{~m} / \mathrm{s}$ \\
3. & $0,6 \mathrm{~m}$ & $0,062 \mathrm{~s}$ & $9,68 \mathrm{~m} / \mathrm{s}$ \\
4. & $0,8 \mathrm{~m}$ & $0,127 \mathrm{~s}$ & $6,30 \mathrm{~m} / \mathrm{s}$ \\
Amount & $2 \mathrm{~m}$ & $0,272 \mathrm{~s}$ & $30,02 \mathrm{~m} / \mathrm{s}$ \\
Average & $0,5 \mathrm{~m}$ & $0,068 \mathrm{~s}$ & $7,505 \mathrm{~m} / \mathrm{s}$ \\
\hline
\end{tabular}

\section{Tracking Speed}

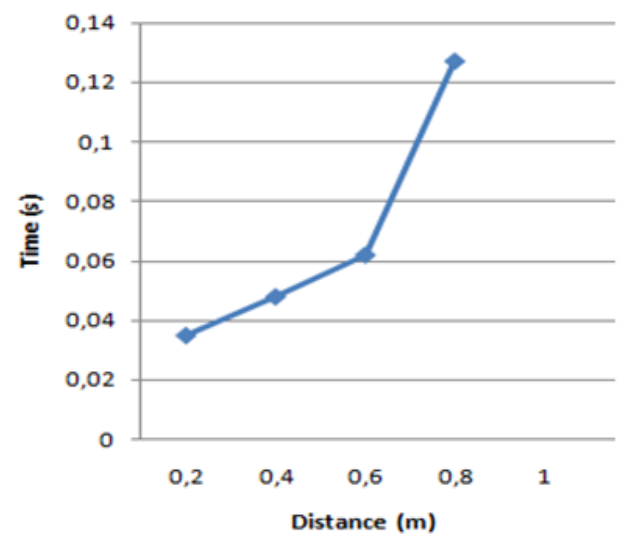

Figure 2. Tracking speed chart

The tracking speed of objects is different. The farther the marker distance with the camera, the longer the object rendering process takes place. 


\subsection{Testing of light intensity}

In testing the intensity of the light, the bigger and the smaller the light can result in the marker image not being captured properly by the camera. Based on Table 5, it is found that in the Augmented Reality program it is better to use it in a place that has moderate lighting which is not too bright and not too dark. This program is well used in dark conditions, which ranges from 01.1 Lux to 03.9 Lux and in bright conditions which range from 15.6 Lux to 1672 Lux.

Table 5. Table light intensity test results

\begin{tabular}{cccc}
\hline No. & Light (Lux) & Description & Status \\
\hline 1. & 00,5 Lux & Very Dark & Not Detected \\
2. & 01,1 Lux & Dark & Detected \\
3. & 03,9 Lux & Dark & Detected \\
4. & 15,6 Lux & Bright & Detected \\
5. & 1672 Lux & Bright & Detected \\
6. & 2160 Lux & Very Bright & Not Detected \\
\hline
\end{tabular}

\subsection{Testing marker reading slope limits}

Testing the slope of marker reading. This is intended to find the deadline for reading the slope which allows for reading the marker. The distance used is as far as $20 \mathrm{~cm}$ from the camera against the marker. Test slope boundary marker reading can be seen in Table 6. It can be seen that the slope of the marker reading only ranges from $0^{\circ}$ to an angle of $45^{\circ}$.

Table 6. Slope test results table for marker reading

\begin{tabular}{cc}
\hline Angle & Description \\
\hline $0^{\circ}$ & Detected \\
$15^{\circ}$ & Detected \\
$30^{\circ}$ & Detected \\
$45^{\circ}$ & Detected \\
$60^{\circ}$ & Not detected \\
\hline
\end{tabular}

\subsection{Testing time tracking}

In testing the tracking time, time measurements are obtained by alternately scanning using 2 devices, namely using a Lenovo 3gb RAM laptop and Android Samsung Grand Prime 1gb RAM. Based on Table 7, it is found that the result of the program tracking time for marker scanning are different because the RAM that the device has is different, In this test, using a Lenovo 3gb RAM laptop compared to Samsung Grand Prime $1 \mathrm{gb}$, which was obtained from the scanning time of the marker as shown in Table 7 and clarified in the tracking time graph in Figure 3.

Based on Figure 3 shows that the program tracking time is faster using a device with $3 \mathrm{gb}$ RAM, the faster device is scanning the marker because a large of RAM will be more flexible in accessing and storing data, such as the function of RAM as temporary memory storage.

Table 7. Tables tracking time test results

\begin{tabular}{ccc}
\hline $\begin{array}{c}\text { Name of Custom } \\
\text { Clothing Marker }\end{array}$ & $\begin{array}{c}\text { Device Camera Scanning Time (seconds) } \\
\text { Laptop Lenovo corei3 } \\
\text { RAM 3 gb }\end{array}$ & $\begin{array}{c}\text { Android Samsung } \\
\text { Grand Prime 1 gb }\end{array}$ \\
\hline Aceh Tamiang & 00.17 & 00.81 \\
East Aceh & 00.18 & 00.57 \\
North Aceh & 00.18 & 00.53 \\
Central Aceh & 00.22 & 00.36 \\
Southeast Aceh & 00.17 & 00.57 \\
West Aceh & 00.22 & 00.41 \\
Aceh Besar & 00.28 & 00.32 \\
South Aceh & 00.35 & 00.57 \\
Amount & 1.77 & 4.14 \\
Average & 0.22 & 0.52 \\
\hline
\end{tabular}




\section{Tracking Time}

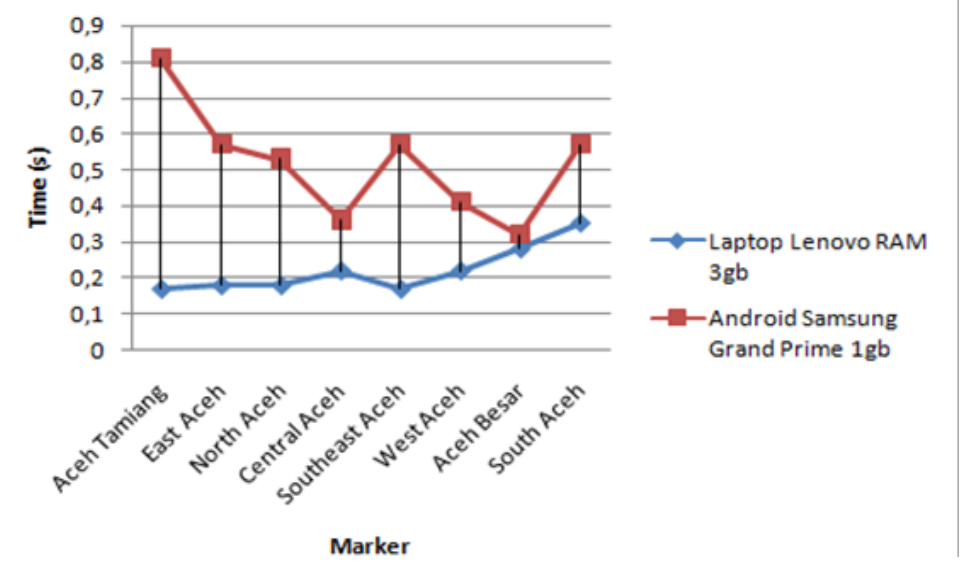

Figure 3. Chart of tracking time

\section{CONCLUSION}

Tracking speed is very influential on distance, the longer the marker distance, the longer the marker tracking process occurs so that if the marker distance with the camera is getting longer, the tracking speed will be longer. The average distance that can detect a marker is $0.5 \mathrm{~m}$, the average detected time is $0.068 \mathrm{~s}$, and the average velocity obtained is $7.505 \mathrm{~m} / \mathrm{s}$.Each marker detected correctly displays a 3D object that matches the marker detected at a distance of $20 \mathrm{~cm}$ to $80 \mathrm{~cm}$ and the marker tilt angle at $0^{\circ}$ to a tilt angle of $45^{\circ}$.

The Augmented Reality program is better to use in places that have moderate lighting which is not too bright and not too dark, this program is well used in dark conditions which ranges from 01.1 Lux to 03.9 Lux and in bright conditions which range from 15.6 Lux to 1672 Lux.The marker reading only ranges from $0^{\circ}$ to an angle of $45^{\circ}$. At the angle of $60^{\circ}$ is not detected because the tilted marker, the camera is difficult to capture the reading pattern in the marker.

From the test results obtained different levels of accuracy, testing markers on the camera obtained an accuracy rate of $100 \%$, testing based on a distance of $80 \%$, testing based on light intensity $66 \%$, and testing the slope limit of $80 \%$. Accuracy of success in each test with an accuracy rate of less than $100 \%$ is due to the pattern in the marker cannot be read clearly by the device's camera, which causes the object cannot be displayed and causes the level of accuracy to be reduced in each test.

\section{REFERENCES}

[1] C. O. Chung, et al., "Augmented Reality Navigation System on Android," International Journal of Electrical and Computer Engineering, vol. 6, no. 1, pp. 406-412, 2016.

[2] I. Tahyudin, et al., "An Interactive Mobile Augmented Reality for Tourism Objects at Purbalingga District," Indonesian Journal of Electrical Engineering and Computer Sciences, vol. 16, no. 3, pp. 559-564, 2015.

[3] H. Subakti, et al., "Engfi Gate: An Indoor Guidance System using Marker-based Cyber-Physical AugmentedReality," International Journal of Electrical and Computer Engineering, vol. 8, no. 1, pp. 34-42, 2018.

[4] K. C. Brata, et al., "Location-Based Augmented Reality Information for Bus Route Planning System," International Journal of Electrical and Computer Engineering, vol. 5, no. 1, pp. 142-149, 2015.

[5] T. Jordine, et al., "A Mobile Device Based Serious Gaming Approach for Teaching and Learning Java Programming," International Journal of Interactive Mobile Technologies (iJIM), vol. 9, no. 1, pp. 53-59, 2015.

[6] A. A. Khairuddin, et al., "Evaluating Students' Emotional Response in Augmented Reality-Based Mobile Learning Using Kansei Engineering," International Conference on User Science and Engineering, pp. 79-89, 2018.

[7] N. M. Noor, et al., "The Potential Use of Augmented Reality in Gamification," Proceedings of the 5th International Conference on Computing and Informatics (ICOCI 2015), pp. 159-167, 2015.

[8] J. W. Greene, "Introduction to mobile augmented reality development in unity," 2016. Available: http://programminghistorian.org/lessons/intro-to-augmented-reality-with-unity.

[9] Y. Levski, "Augmented Reality Takes the Pilot Seat on AR Drones," 2018. Available: https://apprealvr.com/blog/augmented-reality-and-drones/.

[10] E. FitzGerald, et al., "Augmented reality and mobile learning: the state of the art," International Journal of Mobile and Blended Learning, vol. 5, no. 4, pp. 43-58, 2013.

[11] C. Hsu, et al., "Teaching high school computer science with videos of historical figures - An augmented reality approach," 2015 International Conference on Learning and Teaching in Computing and Engineering (LaTiCE 2015), pp. 22-25, 2015. 
[12] N. H. M. Azhar, et al., "Development of augmented reality to learn history," Bulletin of Electrical Engineering and Informatics, vol. 8, no. 4, pp. 1425-1432, 2019.

[13] S. Izzaty, et al., "Augmented reality objects design in augmented story book mobile application for better engagement," International Journal of Electrical and Computer Engineering (IJECE), vol. 9, no. 1, pp. 570-576, 2019.

[14] A. Ihsan, "Learning Media of Mathematical Operations in Early Childhood Based Augmented Reality," International Conference on Science, Technology and Modern Society (ICSTMS), vol. 1, no. 1, pp. 19-22, 2017.

[15] R. Andrea, et al., "Magic Boosed an elementary school geometry textbook with marker-based augmented reality," TELKOMNIKA (Telecommunication Computing Electronics and Control), vol. 17, no. 3, pp. 1242-1249, 2019.

[16] C. Llena, et al., "Implementation of Augmented Reality in Operative Dentistry Learning," European Journal of Dental Education, vol. 22, no. 1, pp. 122-130, 2018.

[17] D. Rohendi, et al., "The Use of Geometry Learning Media Based on Augmented Reality for Junior High School Students," IOP Conference Series: Materials Science and Engineering, vol. 306, no. 1, p. 012029, 2018.

[18] S. Tekkesinoglu, et al., "Towards Building Web Based Augmented Reality Application for Pre-School Children," TELKOMNIKA, vol. 11, no. 6, pp. 3134-3141, 2013.

[19] B. N. Affan, et al., "Implementation of Augmented reality as Information and Promotion Media on Dieng Tourism Area," TELKOMNIKA Telecommunication Computing Electronics and Control, vol. 16, no. 4, pp. 1818-1825, 2018.

[20] R. Setyadi and I. Ranggadara, "Augmented Reality using Featured Accelerated Segment Test for Property Catalogue," TELKOMNIKA Telecommunication Computing Electronics and Control, vol. 18, no. 1, pp. 140-147, 2020.

[21] R. A. Setyawan and A. Dzikri, "Analysis of the Use Marker Tracking Method in Augmented Reality of a Traditional Musical Instrument in Central Java (in Bahasa : Analisis Penggunaan Metode Marker Tracking pada Augmented Reality Alat Musik Tradisional Jawa Tengah)," Jurnal Teknik Industri, Mesin, Elektro, dan Ilmu Komputer (simetris), vol. 7, no. 1, pp. 295-304, 2016.

[22] M. A. Barkah and R. Agustina, "Utilization of Augmented Reality (AR) as an Interactive Learning Media Introduction to Temples in Malang Raya based on Android Mobile (in Bahasa : Pemanfaatan Augmented Reality (AR) sebagai Media Pembelajaran Interaktif Pengenalan Candi-Candi di Malang Raya Berbasis Mobile Android), Bimasakti, vol. 1, no. 5, pp. 1-6, 2017.

[23] H. Vitono, et al., "Implementation of Markerless Augmented Reality as an Android-Based Museum Information Media Collection (in Bahasa: Implementasi Markerless Augmented Reality sebagai Media Informasi Koleksi Museum Berbasis Android),” Jurnal Sistem dan Teknologi Informasi, vol. 4, no. 2, pp. 1-7, 2016.

[24] Y. A. Pramana, et al., "Development of Augmented Reality Applications for Object Recognition in Android Based Museums (Case Study: Blambangan Banyuwangi Museum) (in Bahasa: Pembangunan Aplikasi Augmented Reality untuk Pengenalan Benda di Museum Berbasis Android (Studi Kasus: Museum Blambangan Banyuwangi),” Jurnal Pengembangan Teknologi Informasi dan Komputer, vol. 2, no. 5, pp. 2034-2042, 2018.

[25] I. Mulyana, et al., "Implementation of Natural Feature Tracking on the Introduction of Marine Mammals Based on Augmented Reality (in Bahasa: Implementasi Natural Feature Tracking pada Pengenalan Mamalia Laut Berbasis Augmented Reality)," Seminar Nasional Teknologi Informasi dan Multimedia, pp. 13-18, 2018.

[26] A. P. Andriyandi, et al., "Augmented Reality using Features Accelerated Segment Test for Learning Tajweed," TELKOMNIKA Telecommunication, Computing, Electronics, and Control, vol. 18, no. 1, pp. 208-216, 2020. 